\title{
Dimetiltriptamina: alcalóide alucinógeno e seus efeitos no Sistema Nervoso Central
}

\author{
Darliane Freire de Almeidaa , Ana Ligia Pereira Silvaa, Thais Josy Castro Freire de Assis ${ }^{b^{*}}$ \\ ${ }^{a}$ Universidade Federal de Campina Grande, Campina Grande, 58429-900, Paraíba, Brasil. \\ ${ }^{b}$ Universidade Federal da Paraíba, João Pessoa, 58051-900, Paraíba, Brasil. *thaisjosy@yahoo.com.br
}

Recebido: 11 junho 2017 / Aceito: 2 novembro 2017 / Publicado online: 15 janeiro 2018

\begin{abstract}
Resumo
Plantas alucinógenas são bastante utilizadas em rituais e cultos religiosos. O chá de Ayahuasca e o vinho da Jurema preta, bebidas alucinógenas, apresentam o alcalóide dimetiltriptamina (DMT), responsável pelo efeito alucinógeno devido a interação com receptores serotoninérgicos no sistema nervoso central (SNC). O objetivo da pesquisa foi esclarecer os mecanismos de ação e os efeitos da DMT presente em bebidas alúcinógenas das espécies Mimosa tenuiflora (jurema preta), Banisteriopsis caapi (jagube ou cipó mariri) e Psychotria viridis (chacrona) sobre o SNC, elucidando os riscos da sua ingestão e informações sobre a legislação brasileira. O efeito alucinógeno ocorre a partir da interação dos receptores serotoninérgicos com DMT, esse estruturalmente semelhante a serotonina, o que interfere nas funções psíquicas, proporcionando modificações de dimensões, ilusões acústicas e ópticas, alterações no humor, distorção na percepção do tempo e espaço, despersonalização, midríase e hipertermia. Atualmente existe um acesso a essas substâncias e a difusão do seu uso está em expansão no Brasil, devido a relação com aspectos religiosos e culturais. Dessa forma, é importante conhecer os fatores que englobam o uso dessas substâncias, pois diversas alterações e complicações podem surgir a partir do uso, já que os efeitos alucinógenos provêm de interferências em funções fisiológicas.
\end{abstract}

Palavras-chave: Chá de Ayahuasca, Jurema preta, serotonina, DMT

\section{Dimethyltryptamine: hallucinogenic alkaloid on the Central Nervous System}

\begin{abstract}
Hallucinogenic plants are widely used in rituals and religious cults. Ayahuasca tea and wine black Jurema, both hallucinogenic beverages, present the alkaloid dimethyltryptamine (DMT) responsible for the hallucinogenic effect due to interaction with serotonergic receptors in the central nervous system (CNS). This research aimed to elucidate the mechanisms of action and the effects of DMT present on alumina drinks of the species Mimosa tenuiflora (jurema preta), Banisteriopsis caapi (jagube or cipó mariri) and Psychotria viridis (chacrona) on the CNS, elucidating the risks of their ingestion and information Brazilian legislation. The hallucinogenic effect occurs from the interaction of serotonergic receptors with DMT, this structurally similar to serotonin, which interferes with psychic functions, resulting in changes in dimensions, acoustic and optical illusions, mood alterations, distortion in the perception of time and Space, depersonalization, mydriasis, and hyperthermia. Currently there is free access to these substances and the diffusion of its use is expanding in Brazil due to its relationship with religious and cultural aspects. Thus, it is important to know the factors that encompass the use of these substances, since several alterations and complications can arise from the use, since the hallucinogenic effects come from interferences in physiological functions.
\end{abstract}

Key-words: Ayahuasca tea, Jurema preta, Serotonin, DMT

\section{Introdução}

O uso de plantas alucinógenas é geralmente realizado para a confecção de bebidas, sendo uma prática que vem desde as antigas civilizações (Gaujac, 2013). Dentre elas estão o vinho da Jurema preta no Nordeste e o chá da Ayahuasca na região amazônica. As diferenças entre elas estão no modo do preparo, as culturas que fazem seu uso e a diferença na concentração da DMT, o alcalóide que promove os efeitos alucinógenos de ambas as bebidas (Pires, 2010; Mikosz, 2009).

O chá de Ayahuasca é composto por duas espécies de plantas. A B. caapi ((Griseb. in Mart.) c. v. Morton), um cipó malpighiáceo popularmente chamado de mariri ou jagube, e $P$. viridis Ruiz \& Pavon (folhas do arbusto rubiáceo popularmente chamado de chacrona ou folha-rainha) (Mikosz, 2009). O efeito alucinógeno produzido por esse chá é proveniente da presença da DMT, que tem ação sobre o SNC, promovendo o 
surgimento de alguns sinais e sintomas como palidez, sudorese, midríase, salivação, náuseas, vômitos, diarreia, hipertensão, palpitação, taquicardia, tremores, excitação e alteração na temperatura corpórea (Shanon, 2003, Riba et al., 2003).

A confecção do vinho da $M$. tenuiflora (Willd.) Poir, é feita através do uso dessa planta, que é de grande porte, pertencente da família Fabaceae, predominante da caatinga. Sua estrutura torna esta planta tolerante a grandes períodos de estiagem, característico da região nordeste do Brasil (Maia, 2004). Caracteriza-se por ser uma planta bastante utilizada tanto para fins medicinais como econômicos, onde há uma exploração de sua madeira para o abastecimento de cerâmicas e fabricação do carvão vegetal (Bakker, 2005; Rodrigues e Amador, 2014).

A literatura salienta que diferentemente do chá de Ayahuasca, a Jurema preta apresenta um nível de concentração da DMT muito superior ao de outras plantas e é a principal fonte contemporânea de triptaminas (Gomes, 2008).

A ação da DMT no SNC ocorre devido a sua semelhança estrutural com o neurotransmissor serotonina, interagindo de forma agonista com os receptores 5-HT2 do cérebro (Gil et al., 2014). No entanto, a ação da DMT depende da inibição da monoamina oxidase (MAO), enzima que degrada o alcalóide DMT no fígado e intestino (Pires et al., 2010). No chá da ayahuasca, as folhas da $P$. viridis apresenta grande quantidade da DMT, e a B. caapi apresenta os inibidores de monoaminaoxidase.

A utilização do vinho da Jurema preta fica restrita a indígenas e participantes de religiões que a utilizam como elemento religioso (Carneiro, 2004). Isso é corroborado pela maneira como o vinho é preparado, da necessidade de um "elemento secreto" para que a jurema possa provocar os efeitos alucinógenos desejados, e a ausência/segredo de informações até os dias atuais (Albuquerque, 2002). Diferentemente, o chá de Ayahuasca possui uma legislação que a regulamenta, tendo o CONAD em 2010 ratificado a legitimidade do uso religioso da ayahuasca. A discussão abrange o fato de que apesar da segurança do uso dessas bebidas, o efeito alucinógeno se dá porque existe uma interferência no sistema nervoso central. De forma que, segundo farmacologistas, o uso exagerado dessas substâncias pode levar à depressão permanente e distúrbios diversos em indivíduos suscetíveis, como esquizofrênicos, mas não necessariamente dependência. E a possível liberação do chá do santo daime para o uso fora do ritual, apresenta a possibilidade do uso abusivo (Gomes, 2008; Gios et al., 2016).

A importância de estudos aprofundados sobre essas bebidas alucinógenas se faz necessário, pois o questionamento feito é quais são as reais consequiências do uso dessas substâncias em longo prazo, já que o efeito alucinógeno obtido ocorre a partir da interferência e/ou potencialização de um processo fisiológico. Da mesma forma que esses estudos podem servir também para elucidar possíveis utilizações dessas espécies para fins terapêuticos, tanto em condições físicas ou mentais, partindo do pressuposto dos efeitos provocados por essas substâncias.
Assim, esta pesquisa teve como objetivo esclarecer os mecanismos de ação e os efeitos da DMT presente em bebidas alúcinógenas das espécies $M$. tenuiflora, $B$. caapi e $P$. viridis sobre o SNC, elucidando os riscos da sua ingestão e informações sobre o que rege a legislação brasileira.

\section{Características botânicas e químicas da Banisteriopsis caapi}

Presente na Amazônia encontra-se B. caapi, pertencentente à família malpighiácea, sendo nativa das zonas tropicais da América do Sul e Antilhas (Pires et al., 2010). Os primeiros estudos botânicos sobre $B$. caapi foram realizados durante uma viagem pela Amazônia brasileira, venezuelana e equatoriana entre os anos de 1849 e 1864, pelo inglês Richard Spurce, que a princípio chamou sua atenção, o uso dessa planta em uma bebida chamada ayahuasca (Garrido e Sabino, 2009). Ela apresenta como princípio ativo de sua composição fitoquimica, alcalóides beta carbolinicos que são potentes inibidores da MAO, dentre as principais estão a harmanina (HRM), harmalina (HRL) e a tetrahidroharmina (THH; McKenna, 2004).

\section{Caracteristicas botânicas da Psychotria viridis}

São arbustos e pequenas árvores encontradas em regiões tropicais do mundo todo, apresenta sua taxonomia um pouco complexa, incluindo cerca de 1.400 espécies, dentre elas as do gênero Psychotria cartagenensis e Diplopterys cabrerana, que também podem ser utilizadas no preparo do chá da ayahuasca (Pires et al., 2010).

Essa espécie apresenta como princípio ativo em sua composição fitoquímica alcalóide indol DMT (Gil et al., 2014; Pires et al., 2010). Segundo Tupper (2002), há muitos anos se sabe que o mecanismo de ação dos psicodélicos sobre o sistema nervoso se faz sobre os sistemas da serotonina, devido à semelhança estrutural das duas moléculas.

Esse alcalóide geralmente é encontrado nas folhas da planta e suas concentrações irão variar de acordo com o horário de sua colheita. De acordo com McKenna et al. (1998), $200 \mathrm{~mL}$ de Ayahuasca possui $30 \mathrm{mg}$ de harmina, $10 \mathrm{mg}$ de tetra-hidroharmalina.

\section{Características da Mimosa tenuiflora}

A $M$. tenuiflora é uma das espécies encontradas com frequência na região semiárida brasileira, sendo uma leguminosae da subfamília mimosoideae (Bezerra et al., 2011). Muitas espécies desse gênero apresentam como os principais constituintes químicos os alcalóides, flavonóides, terpenóides e carotenóides (Barbosa-Filho et al., 2008). Bezerra (2008) encontrou em extratos etanólicos da casca, cerne e da folha da jurema preta, metabólitos secundários como taninos hidrolisáveis, flavonas, flavonóides e xantonas, também a presença de triterpenos pentaciclicos, esteróides livres, saponinas e alcalóides. No entanto, alguns metabólicos foram encontrados apenas nos extratos etanóicos do caule e cerne, e outros apenas nos extratos da folha.

A M. tenuiflora foi identificada por Richard Evans Schultes (1993) como possuidora de um alcalóide que a princípio foi 
chamado de nigerina e posteriormente se demonstrou se tratar do alcalóide DMT, o mesmo alcalóide presente nas leguminosas relacionadas com o gênero Anadenanthera (Carneiro, 2004). Esse DMT, substância responsável pela experiência enteógena, está presente em maior quantidade na casca da raiz, mas está igualmente disponível na casca do tronco (Oliveira, 2010).

\section{Chá de Ayahuasca}

O chá de ayahuasca é feito através da fervura da casca do cipó de B. caapi com a mistura de folhas de $P$. viridis (Mikosz, 2009; Souza, 2011; Santos, 2016). É composto pela junção dessas duas plantas. Uma contendo DMT e a outra os inibidores da MAO (iMAO) (Mikosz, 2009).

O seu efeito alucinógeno surge da presença de alcalóides que constituem as propriedades fitoquímicas das plantas utilizadas para a confecção do chá, sendo encontrados no cipó B. caapi a harmanina, a harmalina e a tetrahidroharmina, chamados beta-carbolinas. Essas são os inibidores da MAO encontrados nessa espécie. No arbusto Psychotria viridis, está presente o alcalóide DMT principalmente em suas folhas, sendo este considerado um dos mais potentes alucinógenos naturais encontrados na atualidade (Mikosz, 2009).

Halberstadt et al. (2012) esclarecem que oralmente o alcalóide DMT isolado não é ativo devido ao extenso metabolismo de primeira passagem. No entanto, a harmalina e harmina que são inibidoras da MAO, bloqueiam o catabolismo da DMT. Dessa forma, com a mistura dos extratos das plantas que apresentam DMT com as que contem $\beta$-carbolinas, o alcalóide torna-se ativo oralmente sob a forma de uma infusão ou decocção.

Após o seu preparo, é então engarrafado ainda quente e armazenado. Esse procedimento é uma maneira de evitar a fermentação da bebida, o que causaria um sabor pouco apreciado. Após a administração oral do chá da ayahuasca, os seus efeitos somáticos, como por exemplo, náuseas, formigamentos e aumento da temperatura corporal, surgem em aproximadamente 20 minutos, seguidos dos efeitos cognitivos que só aparecem cerca de 60 a 120 minutos após a ingestão (Garrido e Sabino, 2009). Esses efeitos diminuem gradualmente em aproximadamente 4 horas.

Efeitos como náuseas, vômitos e diarréia são comuns e podem estar associadas à ação no receptor 5-HT2 (Costa et al.; 2005). Além desses efeitos pode surgir a visão de imagens com os olhos fechados, delírios parecidos com sonhos e sensação de vigilância e estimulação. (Costa et al.; 2005). Também podem ocorrer alterações cardíacas como hipertensão, palpitação e taquicardia, além de tremores, midríase, euforia e excitação agressiva (Cazenave, 2000).

O efeito causado está relacionado com dosagem de DMT ingerida, ocasionando os primeiros efeitos cognitivos que fazem com que os objetos pareçam vibrar e aumentar seu brilho e que padrões de movimentos e cenas emergem e são visíveis com olhos abertos ou fechados. Entretanto mesmo havendo esse efeito de alterações físicas e cognitivas os usuários do chá, não ficaram impossibilitados de se localizarem no tempo ou espaço e de falar coerentemente (Garrido e Sabino, 2009).
Apesar de usuários do chá da ayahuasca o considerar seguro para uso, o efeito alucinógeno produzido ocorre a partir de reações no SNC, envolvendo receptores serotoninérgicos, e essas interações podem produzir efeitos adversos importantes.

Sternbach (1991) relata a chamada síndrome serotoninérgica (SS), uma reação adversa, causada pela administração de dois ou mais medicamentos próserotoninérgicos, aumentando assim a concentração de serotonina. Dessa forma, pacientes que estejam em uso de medicamentos inibidores de recaptação de serotonina ou inibidores da MAO não são instruídas a utilizarem concomitantemente com o chá de Ayauhasca. Alguns sintomas da SS são euforia inicial seguida de tremores e convulsões, perda da consciência, agitação, febre, movimentos descoordenados (ataxia) e reflexos alterados.

\section{Vinho da Jurema preta}

O culto da jurema é uma prática religiosa de tradições indígenas que teve origem em tribos do Nordeste, vinculada a espécie de planta também denominada de jurema, árvore presente nas regiões nordestina, sendo característica da caatinga (Santiago, 2008). Acredita-se que essa prática tenha surgido do contato dos índios com colonos portugueses e negros, a qual surgiu a figura do caboclo, uma entidade bastante respeitada por seus poderes de cura, nas reuniões de catimbó e pajelança, no Nordeste e Norte do país. Esses caboclos foram sendo introduzidos nos rituais da umbanda e candomblé, onde são realizadas cerimônias em sua homenagem, sempre com a presença do vinho da jurema (Camargo, 2014). A princípio todas as plantas americanas que continham em sua composição química o alcalóide alucinógeno DMT e que eram consideradas sagradas para os indígenas, foram alvo de perseguições pela igreja católica e pela administração colonial (Oliveira, 2010).

O culto e a utilização de partes dessa árvore, durante os rituais religiosos dos nativos brasileiros, podem ser constatados nos escritos de Oliveira (1992), Cascudo (1978), Herckmam (1982), Nascimento (1994), Mota (1987) e Vandezande (1975). Estes se referem à confecção de uma bebida sagrada a partir da casca, tronco e raízes da referida planta. Quando ingerida, acredita-se que tal bebida possui a propriedade de transportar os homens para o mundo do além, possibilitando-os a comunicação com os seres que lá habitam (Santiago, 2008).

De acordo com a literatura, os grupos indígenas utilizam a jurema com umas das formas análogas do uso de alucinógenos, e que além da jurema também utilizam outras fontes naturais da DMT, como a ayahuasca ou rapés, bebidas que também apresentam efeitos psicodélicos (Carneiro, 2004).

A forma como se prepara o vinho da jurema varia consideravelmente entre os indígenas e os cultos afrobrasileiros, tendo cada um desse contexto uma metodologia própria de confeccionar a bebida, porém possui em comum a planta jurema como ingrediente obrigatório. Sobre a maneira como é preparado as informações disponíveis são muito escassas, por se manter ater os dias de hoje em segredo (Albuquerque, 2002).

Assim, de acordo com a literatura sobre o vinho da jurema, sabe-se que a maneira como os mestres e representantes das 
religiões associadas a jurema preparam o vinho não é muito esclarecida. Não se sabe ao certo se há a utilização de uma segunda planta ou plantas, que em mistura com a jurema, potencializam seu efeito alucinógeno. Levando em consideração que DMT não age por via oral, acredita-se que há uma associação da jurema com uma espécie de arruda da síria, e que esta possuiria os componentes necessários para inibição da enzima MAO, provocando assim o seu efeito (Carneiro, 2004).

Como a ação da DMT é degradada no fígado e intestino por uma enzima natural do organismo humano, a MAO (Pires et al., 2010), os indígenas aprenderam a combinar DMT com substâncias que contém $\beta$-carbolinas, permitindo que o alcalóide promova o seu efeito alucinógeno. A combinação de outras plantas com a jurema é de total conhecimento apenas dos indígenas e participantes de religiões que a utilizam (Carneiro, 2004).

A ingestão do vinho da jurema e sua interação com o organismo provocam diversos efeitos psíquicos e também físicos, entre eles distorção de percepção de tempo, espaço, forma e cores, alucinações visuais, ideias delirantes de grandeza ou de perseguição, despersonalização, midríase, hipertermia, taquicardia e aumento da pressão arterial (Martinez et al., 2009). Os efeitos causados devem-se a presença da DMT, um alucinógeno capaz de interferir no estado de consciência produzindo alterações de percepção, o que seria um dos fatores pelas quais ela é utilizada em rituais religiosos por vários grupos, por proporcionar uma aproximação com o estado espiritual (Martinez et al., 2009).

\section{Mecanismo de ação da DMT}

Para entender o mecanismo de ação da DMT no cérebro é importante o conhecimento sobre os neurotransmissores e seus receptores no SNC. A DMT irá competir com a serotonina e irá se ligar nos seus respectivos receptores.

A serotonina hidroxitriptamina ou 5-HT é um neurotransmissor secretado por neurônios serotoninérgicos e age nos receptores de neurônios pós-sinápticos (Costa et al., 2005). A 5-HT é uma indolamina, produto da hidroxilação e carboxilação do aminoácido triptofano e é produzida nos núcleos da rafe. É sintetizada a partir do aminoácido triptofano pela enzima triptofanohidroxilase (TPH), que converte o triptofano em 5-hidroxitriptofano em serotonina. Essas enzimas são encontradas no citoplasma dos neurônios serotoninérgicos, tanto no corpo celular quanto nos processos celulares. A serotonina é concentrada e armazenada no interior de vesículas localizadas no axônio, corpos celulares e dendritos (Nadal-Vicens et al., 2009). As ações da serotonina ocorrem em decorrência da interação desse neurotransmissor com os receptores serotoninérgicos.

O receptor 5-HT1a se distribui pelos núcleos da rafe e hipocampo, atuando na diminuição do AMP cíclico (adenosina 3', 5'-monofosfato cíclico) e elevando a hiperpolarização da membrana causada pelo aumento das condutâncias de $\mathrm{K}^{+}$.

$\mathrm{O}$ receptor 5-HT1b está presente no globo pálido e gânglios da base e sua estimulação leva a diminuição do AMPc.
O receptor 5-HT1c ocorre no coróide e hipocampo gerando também, o aumento do IP3 (inositol trifosfato) nesses locais.

O 5-HT2 se distribuem nas plaquetas, músculo liso, córtex cerebral e fundo do estomago, causando o aumento do IP3, esse aumento significa, ao final desse mecanismo, há o aumento da secreção e do movimento desse órgão e tecidos (Costa et al., 2005; Nadal-Vicens et al., 2009).

Os receptores 5-HT3 são canais iônicos, que estão presentes nas estruturas corticais e subcorticais, a estimulação desses receptores provoca a abertura do seu canal possibilitando a entrada de correntes catiônicas gerando uma rápida resposta despolarizante no sistema nervoso central e periférico (Batista, 2012).

Os restantes dos tipos de receptores estão associados a estimulação da adenilil ciclase, embora ainda haja subtipos de receptores que não estão totalmente caracterizados (NadalVicens et al., 2009).

Esse neurotransmissor desempenha um importante papel no sistema nervoso, atuando na liberação de alguns hormônios, regulação do sono, temperatura corporal, apetite, humor, atividade motora, e funções cognitivas (Feijó et al., 2011).

As concentrações de serotonina cerebral estão relacionadas a algumas alterações comportamentais, assim como no nosso humor, ansiedade, agressividade e no apetite. Também está relacionada à regulação da temperatura e da pressão arterial e na percepção de dor (Costa et al., 2005; Nadal-Vicens et al., 2009; Batista, 2012; Betran e Katzung, 2014; Souza, 2011.). A serotonina influi em quase todas as funções cerebrais, inibindo e modulando as atividades psíquicas, sendo a substância que mais predomina entre os neurotransmissores (Souza, 2011).

\section{DMT e o SNC}

DMT é um psicoativo da família triptamina, um alcaloide indólico com acentuada ação psicoativa, presente em bebidas vegetais de origem indígena, como o vinho da jurema e a ayahuasca (Gaujac, 2013). Esse alcalóide interage nos receptores serotoninérgicos, por ser considerado um agonista da serotonina, apresentando afinidade por esses receptores e estimulando atividades fisiológicas, provenientes dessa interação, simulando o efeito do neurotransmissor (Maia, 2004). Essa interação se dar devido as moléculas da DMT serem similares as moléculas da serotonina e interagem com os mesmos receptores 5-HT2 do cérebro (Gil et al.; 2014).

Esse alcalóide apresenta psicoatividade apenas quando administrada via endovenosa, intramuscular, subcutânea ou pelas vias aéreas (McKenna, 2004). Quando são consumidas via oral, a MAO associa-se a essas moléculas impedindo que passem para a circulação sanguínea e alcancem o sistema nervoso central (SNC). Assim, a MAO controla os níveis de concentração de alguns neurotransmissores, sendo capaz de metabolizar triptaminas, como a melatonina, serotonina e DMT (Gaujac, 2013). Entretanto o seu efeito por via oral só se dar com a associação da DMT com inibidores da MAO, geralmente encontrados em algumas espécies vegetais.

Esses inibidores da MAO também podem ser encontrados em alguns tipos de anti-depressivos como por exemplo a fenelzina, tranilcipromina, isocarboxazid, selegilina e moclobemida. Indivíduos que apresentem algum tipo de 
distúrbios como a esquizofrenia em sua história familiar, com tendências à psicose depressiva ou ainda em estado emocional fragilizado, devem evitar o contato com psicodélicos, pois eles podem intensificar a manifestação desses desequilíbrios (Jacob e Presti, 2005).

DMT é endógeno e interage com receptores específicos no cérebro, produzindo um estado de relaxamento mental capaz de minimizar os sintomas da psicose, e que o aumento dos níveis da DMT no cérebro, durante uma forte situação de estresse, caracterizaria como um ansiolítico endógeno (Jacob e Presti, 2005). Causa intensos distúrbios visuais e forte estado mental psicodélico quando fumado, injetado ou quando utilizado juntamente com um inibidor da MAO. Apresentam visão de imagens com os olhos fechados, delírios parecidos com sonhos e sensação de vigilância e estimulação. Também é comum ocorrer hipertensão, palpitação, taquicardia, tremores, midriase, euforia e excitação agressiva (Costa et al, 2005).

DMT tem seu efeito potencializado quando usado por via parenteral na dosagem de $25 \mathrm{mg}$. A interação com organismo atribui a esse alcalóide afinidade pelos receptores 5-HT1a, 1b, $1 d$ e do 5-HT2a e 2c. Os efeitos provenientes dessa interação aparecem de 30 a 45 minutos, aproximadamente, e podem durar até quatro horas (McKenna, 2004).

Estudos utilizando a quantificação neuronal no córtex cerebral de camundongos sob o uso do chá de ayahuasca, que contém o mesmo psicoativo DMT, concluiu que a ação da bebida no SNC deu-se devido à interação da $\beta$-carbolinas com a DMT presente nas plantas (Correa et al., 2014). Juntas potencializaram as propriedades alucinógenas, levando-se em consideração que a $\beta$-carbolina aumenta as concentrações da DMT podendo provocar distúrbios comportamentais, mas não morfológicas ou quantitativas das células nervosas. As $\beta$ carbolinas também possuem propriedades alucinógenas o que contribuiriam na potencialização alucinógena da bebida (Cazenave, 1996a). Como são inibidoras da MAO, as $\beta$ carbolinas evitam que as moléculas de DMT sejam quebradas pela MAO ainda no intestino, possibilitando a chegada ao sistema nervoso central, mesmo sendo ingerida por via oral (Callaway et al., 1999). Além disso, esses inibidores desempenham a função de estimular o aumento dos níveis de neurotransmissores como a serotonina, dopamina, norepinefrina e epinefrina no cérebro (Costa et al., 2005).

Um desses inibidores, especificamente a tetra-hidroharmina, o segundo alcalóide mais presente no chá, atua inibindo a atividade da enzima de recaptação da serotonina, assim como a inibição da enzima MAO, o que ocasiona uma prolongação do efeito da DMT no SNC (Costa et al., 2005).

\section{Legislações aplicadas ao uso do chá da ayahuasca}

Pesquisadores criaram o termo enteógeno, que segundo Tupper (2002), surgiu para substituir o termo psicodélico, e assim designar de forma apropriada plantas e substâncias reverenciadas em rituais tradicionais, referindo-se a um instrumento espiritual e sacramental. A palavra enteógeno é utilizada para designar estados xamânicos induzidos pela ingestão de substância que alteram o estado de consciência (Teixeira, 2007) e significa literalmente "manifestação interior do divino".
O uso de drogas na sociedade difere em duas situações, há o uso feito pela sociedade em geral que se dar de maneira recreacional e aditiva, enquanto o uso religioso está associado ao sagrado, a contemplação e autoconhecimento (Teixeira, 2007). Geralmente o uso de drogas feitas pelas religiões é oriundo de fontes naturais como vegetais por exemplo. Mesmo o Brasil ainda sendo um país majoritariamente cristão, onde predomina o catolicismo, está apresentando um espectro de alternativas religiosas, ou seja, o Brasil deixou de ser um pais essencialmente católico (Teixeira, 2007).

De acordo com as referencias, em 1985 umas das plantas (B. caapi), que constituem o chá da ayahuasca foi inserida na lista de produtos prescritos através da portaria $n^{\circ} 2 / 85$ da divisão de medicamentos (DIMED), órgão responsável na época por elaborar a lista de substâncias proscritas e de uso controlado no Brasil, onde a ayahuasca permaneceu proibida até o início de 1986 (Antunes, 2015).

Assim, depois de muitos embates com órgão legislativos o seu uso foi regulamentado pela resolução $\mathrm{n}^{\circ} 5$ do conselho nacional de políticas sobre drogas (CONAD) de 4 de novembro de 2004. Também recentemente o CONAD publicou a resolução $\mathrm{n}^{\circ} 1$ de 25 de janeiro de 2010, que ratificou a legitimidade do uso religioso da ayahuasca que já havia sido reconhecido pela resolução anterior de 2004 e do relatório final do grupo multidisciplinar de trabalho (GMT) de 2006 (Garrido e Sabino, 2009).

Dessa forma, o item 8 e 9 do relatório final do GMT de 23 de novembro de 2006, pauta para o cadastramento das entidades, os aspectos jurídicos e legais para regulamentação do uso religioso e amparo ao direito à liberdade de culto assim como regulação de preceitos para produção, uso, envio e transporte da ayahuasca, procedimentos de recepção de novos interessados na pratica religiosa, também definições do uso terapêutico e outras questões cientificas (Garrido e Sabino, 2009).

O uso de enteógenos é incompreensível pela maioria da população, onde os mesmos usam argumentos que acusam uma drogadição disfarçada, um desvio de caráter ou uma ameaça, se tratando de uma substância que altera o estado mental, acaba não sendo bem vista diante a sociedade tradicional (Teixeira, 2007). Porém no que se diz respeito à liberdade religiosa, o chá da ayahuasca, considerado uma bebida enteógena, encontra-se liberado apenas para o contexto religioso, mesmo que ainda haja um uso ilegal do mesmo, isso se deve a fácil disponibilidade dos vegetais que compõem as bebidas alucinógenas, que são comercializados principalmente no âmbito virtual (Gaujac, 2013).

\section{Referências}

Albuquerque, U.P. 2002. As muitas faces da Jurema: de espécie botânica a divindade afro-indígena. Bagaço: Recife, 192 p.

Antunes, H.F. 2015. Religiões e controvérsias públicas, praticas sociais e discurso.1ed. Ed Unicamp: São Paulo, 19 p.

Bakker, I.A. 2005. Potencial de Acumulação de fitomassa e composição bromatológica da $M$. tenuiflora (Willd.) Poiret. na região semi-árida da Paraíba. Tese de doutorado, Universidade Federal da Paraíba, Areia, Paraiba. 92f

Barbosa-Filho, J.M.; Alencar, A.A.; Nunes, X.P.; Tomaz, A.C.A.; Sena-Filho, J.G.; Athayde-Filho, P.F.; Silva, M.S.; Souza M.F.V.; da-Cunha E.V.L. 2008. Sources of alpha-, beta-, gamma-, delta- and epsilon-carotenes: A twentieth century review. Revista Brasileira de Farmacognosia, 
18(1):135-154

Batista, A.S. 2012. Papel dos receptores do tipo 5-HT3 na área septal media sobre o controle da pressão sanguínea, do apetite por sódio e da ingestão hídrica. Dissertação de Mestrado, Universidade Federal da Bahia, Salvador, Bahia. 62f.

Bertram, G.; Katzung, M.D. 2014. Histamina, Serotonina e alcalóides do esporão do centeio (ergot). In. Bertram et al. (12 ed). Farmacologia Básica e clinica. AMGH, Porto Alegre, p. 271-293.

Bezerra, D.; Rodrigues, F.; Costa, J.; Pereira, A.; Sousa, E.; Rodrigues, O. 2011. Abordagem fitoquimica, composição bromatologica e atividade antibacteriana da M. tenuiflora (Wild) Poir e Piptadenia stipulacea (Benth) Ducke. Acta Sientiarium. Biological sciences, 33(1): 99-106.

Bezerra, D.A.C. 2008. Estudos fitoquímicos, bromatologicos e microbiológicos de M. tenuiflora (Wild) Poir e P. stipulacea (Benth) Ducke. Dissertação de Mestrado, Universidade Federal de Campina Grande, Patos, Paraíba. 49f.

Callaway, J.C.; McKenna, C.S.; Grob, G.S. 1999. Pharmacokinetics of Hoasca alkaloids in healthy humans. Journal of Ethopharmacology, 65(3): 243-256.

Camargo, M. Contribuição ao estudo etnofarmacobotânico da bebida ritual de religiões afro brasileiras denominada "vinho da Jurema" e seus aditivos psicoativos. 2014. Revista do Núcleo de Estudos de Religião e Sociedade (NURES), 26: 1-20

Carneiro, H. 2004. As plantas sagradas na história da América. Varia Historia, 32: 102-119.

Cazenave, S.O.S. 1996. Alucinógenos. In: Olga, S. Fundamentos de Toxicologia, Atheneu, São Paulo, p. 329-43.

Cazenave, S.O.S. 2000. B. caapi: ação alucinógena e uso ritual. Revista de Psiquiatria Clínica, 27(1): 1-6.

Correa, J.; Amorim, V.; Nogueira, D.; Soares, E.; Guerra, F.; Fernandes, J.; Junior, W.; Esteves, A. 2014. Quantificação neuronal no córtex cerebral de camundongos sob o uso do chá de Ayahuasca. Revista Neurociências, 22(3): 388-391.

Costa, M.; Figueiredo, M.; Cazenave, S. 2005. Ayahuasca: uma abordagem toxicológica do uso ritualístico. Revista Psiquiatria Clinica, 32(6): 1-12.

Feijó, F.; Bertoluci, M.; Reis, C. 2011. A serotonina e controle hipotalâmico da fome: uma revisão. Revista de Associação Médica Brasileira, 57(1): 74-77.

Garrido, R.G.; Sabino, B. D. 2009. Ayahuasca: entre o legal e o cultural. Revista Saúde, Ética e Justiça, 14(2): 44-53.

Gaujac, A. 2013. Estudos sobre o psicoativo DMT em M. tenuiflora (Willd.) Poiret e em bebidas consumidas em contexto religioso. Tese de doutorado, Universidade Federal da Bahia, Salvador, Bahia. $183 \mathrm{f}$. Revista eletrônica de Analises Clínicas, 6:1-15.

Gil, G.; Gimenez. J.; Sauez, C. 2014. Drogas alucinógenas e sua detecção laboratorial. Revista eletrônica de Analises Clínicas, 6:1-15.

Gios, S.T.; Pinheiro, M.C.P.; Calfat, E.L.B. 2016. Sintomatologia psicótica e ayahuasca: relato de caso. Revista Debates em Psiquiatria, 6(2): 38-41.

Gomes, M. 2008. Dietilamida do ácido lisérgico (LSD) e DMT como substrato de perioxidases: uma possível rota de metabolização. Dissertação de mestrado, Universidade de São Paulo, São Paulo, São Paulo.102f.

Halberstadt, A.L.; Nichols, D.E.; Geyer, M.A. 2012. Behavioral effects of $\alpha, \alpha, \beta, \beta$-tetradeutero-5-MeO-DMT in rats: comparison with 5-MeODMT administered in combination with a monoamine oxidase inhibitor. Psychopharmacology (Berl), 221(4): 709-718.

Jacob, M.; Presti, D. 2005. Endogenous psychoactive tryptamines reconsidered: na anxiolytic role for dimethyltryptamine. Medical Hypotheses, 64(5): 930-937.

Maia, G.N. 2004. Caatinga: árvores e arbustos e suas utilidades. 1ed. D\&Z Computação, São Paulo, 413 p.

Martinez, T.; Almeida, M.; Pinto, A. 2009. Alucinógenos naturais: um vôo da Europa medieval ao Brasil. Química Nova, 32(9): 2501-2507.

McKenna, D.J.; Callaway, J.C.; Grob, C.S. 1998. The scientific investigation of Ayahuasca: a review of past and current research. The Heffer Review of Psychedelic Reseach, 1: 65-76.

McKenna, D.J. 2004.Clinical investigations of the therapeutic potential of Ayahuasca: rationale and regulatory challenger. Pharmacology and
Therapeutics, 102(2): 111-129.

Mikosz, J.E. 2009. A arte visionaria e a Ayahuasca: representações visuais de espirais e vórtices inspiradas nos estados não ordinários de consciência. Tese de Doutorado, Universidade Federal de Santa Catarina, Florianopólis, Santa Catarina. 297f.

Nadal-Vicens, M.; Chyung, J.H.; Turner, T.J. 2009. Farmacologia da neurotransmissão serotoninérgica e adrenérgica central. In: Golan, D.E. et al. Princípios de Farmacologia: a base fisiopatológica da farmacoterapia. 2ed. Rio de Janeiro: Guanabara Koogan. p. 186-202.

Oliveira, I.L. 2010. Breve histórico da ressignificação da ayahuasca na religião santo daime. Revista Internacional Interdisciplinar Interthesis,7(2): 316342 .

Pires, A.; Oliveira, C.; Yonamine, M. 2010. Ayahuasca: uma revisão dos aspectos farmacológicos e toxicológicos. Revista de Ciências Farmacêuticas Básica e Aplicada,31(1): 15-23.

Riba, J.; Valle, M.; Urbano, G.; Yritia, M.; Morte, A.; Barbanoj, M.J.; 2003. Human pharmacology of ayahuasca: subjective and cardiovascular effects, monoamine metabolite excretion, and pharmacokinetics. Journal Pharmacology Experimental Therapeutics, 306(1): 73-83.

Rodrigues.R.; Amador.M. 2014. Estudo das utilizações da M. tenuiflora no espaço agrário de São João- PE na perspectiva sistêmica. Revista diálogos, 11: 127-144.

Santiago, I.M.F.L. 2008. A jurema sagrada da Paraíba. Revista eletrônica Qualitas 7(1):1-14.

Santos, A.F.A. 2016. Avaliação toxicológica da ayahuasca em ratos wistar: comportamento e toxicidade reprodutiva em machos. Dissertação de Mestrado, Universidade de Brasilia, Brasilia, Distrito Federal. 96f.

Shanon, B. 2003. Os conteúdos das visões da ayahuasca. Mana 6(2): 109-152.

Souza, P.A. 2011. Alcalóides e o chá da ayahuasca: uma correlação dos "estados alterados da consciência" induzidos por alucinógenos. Revista Brasileira de Plantas Medicinais, 13(3): 349-358.

Sternbach, H. The Serotonin Syndrome. American Journal of Psychiatry, 148: 705, 1991.

Teixeira, D.E. 2007. O direito ao uso de enteógenos. Dissertação de Mestrado, Universidade Católica do Rio Grande do Sul, Porto Alegre, Rio Grande do Sul. $25 \mathrm{f}$.

Tupper, K.W. 2002. Entheogens and existential intelligence: the use of plant teachers as cognitive tools. Canadian Journal of Education, 27(4): 499516. 